P9 VALIDATION OF THE ADJUSTED GLOBAL ANTIPHOSPHOLIPID SYNDROME SCORE AND CORRELATION WITH EXTRA-CRITERIA MANIFESTATIONS

${ }^{1}$ Omer Uludag, ${ }^{2}$ Murat Bektas, ${ }^{3}$ Erhan Cene, ${ }^{2}$ Yasemin Sahinkaya, ${ }^{2}$ Ahmet Gul, ${ }^{2}$ Lale Ocal, ${ }^{2}$ Murat Inanc, ${ }^{2}$ Bahar Artim-Esen. ${ }^{1}$ Dept. of Internal Medicine, Istanbul Faculty of Medicine, Istanbul University, Istanbul; ${ }^{2}$ Division of Rheumatology, Dept. of Internal Medicine, Istanbul Faculty of Medicine, Istanbul University, Istanbul; ${ }^{3}$ Dept. of Statistics, Faculty of Arts and Science, Yildiz Technical University, Istanbul, Turkey

10.1136/lupus-2020-eurolupus.58

Background/Purpose Adjusted global antiphosholipid syndrome score (aGAPSS) is the simplified version GAPSS that was recently developed to assess thrombotic risk by the consideration of antiphospholipid antibody (aPL) profile and conventional cardiovascular risk factors. The aim of this study was to evaluate the validity of the aGAPSS in predicting thrombosis and extra-criteria manifestations in our antiphospholipid syndrome (APS) cohort.

Abstract P9 Table 1 Demographic, laboratory and clinical characteristics of patients

\begin{tabular}{|c|c|c|c|c|}
\hline & $\begin{array}{l}\text { Total } \\
\text { population } \\
(n=98) \\
n(\%)\end{array}$ & $\begin{array}{l}\text { PAPS } \\
(n=42) \\
n(\%)\end{array}$ & $\begin{array}{l}\text { SLE/APS } \\
(n=56) \\
n(\%)\end{array}$ & $P$ \\
\hline Female & $83(84.7)$ & $36(85.7)$ & $47(83.9)$ & 0.52 \\
\hline Age, years $($ mean $\pm S D)$ & $42.4(10.9)$ & $44.6(11.6)$ & $40.8(10.1)$ & 0.42 \\
\hline $\begin{array}{l}\text { Disease duration, years } \\
(\text { mean } \pm S D)\end{array}$ & $9.8(7.8)$ & $10(8.8)$ & $9.7(7.1)$ & 0.16 \\
\hline Thrombosis & $87(88.8)$ & $35(83.3)$ & $52(92.9)$ & 0.12 \\
\hline - Arterial & $58(66.7)$ & $24(68.6)$ & $34(65.4)$ & 0.47 \\
\hline - Venous & $45(51.7)$ & $19(54.3)$ & $26(50)$ & 0.43 \\
\hline - Recurrent & $\underline{37(42.5)}$ & $\underline{15(42.9)}$ & $\underline{22(42.3)}$ & 0.56 \\
\hline $\mathrm{o} A \rightarrow \mathrm{V}$ & $3(8.1)$ & $2(13.3)$ & $1(4.5)$ & \\
\hline$\circ \mathrm{V} \rightarrow \mathrm{A}$ & $15(40.5)$ & $6(40)$ & $9(40.9)$ & \\
\hline $0 \mathrm{~A} \rightarrow \mathrm{A}$ & $9(24.3)$ & $2(13.3)$ & $7(31.8)$ & \\
\hline$\circ \mathrm{V} \rightarrow \mathrm{V}$ & $10(27)$ & $5(33.3)$ & $5(22.7)$ & \\
\hline Pregnancy morbidity & $40(40.8)$ & $20(47.6)$ & $20(35.7)$ & 0.16 \\
\hline$\cdot<10$ weeks, $\geq 3$ & $9(22.5)$ & $5(25)$ & $4(20)$ & 0.5 \\
\hline abortions & $29(72.5)$ & $14(70)$ & $15(75)$ & 0.5 \\
\hline$\cdot \geq 10$ weeks, $\geq 1$ & $8(20)$ & $3(15)$ & $5(25)$ & 0.34 \\
\hline abortion & $6(15)$ & $1(5)$ & $5(25)$ & 0.09 \\
\hline \multicolumn{5}{|l|}{ - Pre-eclampsia/eclampsia } \\
\hline \multicolumn{5}{|l|}{ - $<34$ weeks, $\geq 1$} \\
\hline \multicolumn{5}{|l|}{ premature birth } \\
\hline Livedo reticularis & $11(11.2)$ & $2(4.8)$ & $9(16.1)$ & 0.07 \\
\hline Thrombocytopenia & $33(33.7)$ & $9(21.4)$ & $24(42.9)$ & 0.02 \\
\hline APS nephropathy & $9(9.2)$ & $2(4.8)$ & $7(12.5)$ & 0.17 \\
\hline Valvular heart disease & $33(33.7)$ & $12(28.6)$ & $21(37.5)$ & 0.24 \\
\hline Conventional risk factors & $53(53.1)$ & $17(40.5)$ & $35(62.5)$ & \\
\hline - Arterial hypertension & $47(48)$ & $21(50)$ & $26(46.4)$ & 0.02 \\
\hline - Hyperlipidemia & $6(6.1)$ & $3(7.1)$ & $3(5.4)$ & 0.41 \\
\hline - Diabetes mellitus & $35(35.7)$ & $19(45.2)$ & $16(28.6)$ & 0.51 \\
\hline - Obesity & $30(30.6)$ & $12(28.6)$ & $18(32.1)$ & 0.07 \\
\hline - Smoking & & & & 0.43 \\
\hline aPL profile & 77 (78.6) & $29(69)$ & $48(85.7)$ & \\
\hline - LA & $59(60.2)$ & $31(73.8)$ & $28(52.8)$ & 0.04 \\
\hline - $\mathrm{aCL} \lg \mathrm{G} / \lg \mathrm{M}$ & $49(50)$ & $22(56.4)$ & $27(52.9)$ & 0.03 \\
\hline • aß2GPI IgG/IgM & $30(30.6)$ & $14(33.3)$ & $17(30.4)$ & 0.45 \\
\hline - Triple positive & & & & 0.46 \\
\hline
\end{tabular}

Methods Ninety-eight patients with APS were classified according to clinical manifestations as vascular thrombosis (VT), pregnancy morbidity (PM) or both $(\mathrm{VT}+\mathrm{PM})$. The aGAPSS was calculated as defined before. Arterial hypertension and hyperlipidemia definitions were made according to the ESC/ ESH ve NCEP/ATP III guidelines, respectively.

Results Demographic, laboratory and clinical characteristics of patients are summarized in table 1. Mean aGAPSS was calculated as $10.2 \pm$ 3.8. Significantly higher aGAPSS values were seen in VT $(n=58)$ and VT+PM $(n=29)$ compared to PM $(n=11)$ (mean aGAPSS $10.6 \pm 3.7$ vs $7.3 \pm 2.9, P=0.005$; $10.5 \pm 4$ vs $7.3 \pm 2.9, P=0.01$, respectively). AUC demonstrated that aGAPSS values $\geq 10$ had the best diagnostic accuracy for thrombosis (AUC: 0.71, sensitivity: 0.52, specificity: 0.91, $P=0.01)$. Higher aGAPPS values were also associated with recurrent thrombosis (mean aGAPSS $11.5 \pm 3.7$ vs 9.9 \pm 3.6, $P=0.04)$. Regarding extra-criteria manifestations, patients with livedo reticularis $(n=11)$ and APS nephropathy $(n=9)$ had significantly higher aGAPSS values (mean aGAPSS $12.9 \pm 3.4$ vs $9.9 \pm 3.7, P=0.02 ; 12.4 \pm 2.9$ vs $10 \pm 3.8$, $P=0.04$, respectively).

Conclusion Our results suggest that patients with higher aGAPSS values are at higher risk for developing vascular thrombosis (either single or recurrent) and extra-criteria manifestations, especially livedo reticularis and APS nephropathy.

\section{P10 ANTIPHOSPHOLIPID ANTIBODIES ASSOCIATED EXTRA- CRITERIA CLINICAL MANIFESTATIONS SHOULD NOT BE IGNORED}

Jiuliang Zhao, Chaojun Hu, Can Huang, Xinping Tian, Mengtao Li, Xiaofeng Zeng. Dept. of Rheumatology, Peking Union Medical College Hospital, Beijing, China

\subsection{6/lupus-2020-eurolupus.59}

Background The current Sydney classification criteria do not consider a range of non-thrombotic clinical manifestations that are frequently observed in association with the presence of aPLs, the so-called extra-criteria manifestations. The aim of this study was to retrospectively analysis our single center Antiphospholipid antibodies associated clinical phenotypes, especially the frequency of extra-criteria manifestations.

Methods Data of 731 serum samples from patients of clinical suspected APS in 2018 were enrolled. Data of clinical features, laboratory examination, treatment and prognosis were retrospectively analyzed.

Results A total of 200 patients with APLs were positive (27\%), 56 males and 144 females, with an average age of $40.13 \pm 17.24$ years, 115 cases $(57.5 \%)$ with ACL positive, 167 cases $(83.5 \%)$ with anti- $\beta 2$ GPI antibodies positive, 69 cases $(34.5 \%)$ with LA positive, and 20 cases (10\%) turned negative after 12 weeks without any specific therapy. 61 $(30.5 \%)$ patients were fulfilled the 2006 revised Sydney classification criteria for APS. One patient was Catastrophic APS. 27(44.3\%) patients with primary APS, 34 (55.6\%) were secondary APS, including SLE-APS (20), CTD (9), infection (3), malignancies (2). 119 patients with persistent APLs positive, but were not fulfilled the APS criteria because of without thrombosis or fetal loss. 77 (42.8\%) patients were asymptomatic, 42 patients with extra-criteria manifestations. The total frequency of extra-criteria manifestations associated with APLs are 40\%. The details are shown in table 1 . 